\title{
Treatment of Circumscribed Juvenile Type of Pityriasis Rubra Pilaris with Calcipotriol: A Case Report
}

\author{
Fitriani Fitriani ${ }^{1}$, Nina Roiana ${ }^{1}$, Hari Darmawan ${ }^{1,{ }^{*}}$, Inda Astri Aryani ${ }^{1}$ and Soenarto Kartowigno ${ }^{1}$ \\ ${ }^{1}$ Department of Dermatovenereology, Faculty of Medicine, Dr. Mohammad Hoesin General Hospital, Sriwijaya University, Palembang, Indonesia \\ "Corresponding author: Department of Dermatovenereology, Faculty of Medicine, Dr. Mohammad Hoesin General Hospital, Sriwijaya University, Palembang, Indonesia. Email: \\ dr.haridarmawan@yahoo.com
}

Received 2019 December 18; Revised 2020 February 17; Accepted 2020 March 02.

\begin{abstract}
Introduction: Pityriasis rubra pilaris (PRP) is a group of chronic papulosquamous disorders manifesting hyperkeratotic follicular papules and forming salmon-colored plaques with white scales. It is a rare case worldwide even in Indonesia.

Case Presentation: We report a case of circumscribed juvenile PRP in a four-year-old boy successfully treated with calcipotriol ointment.

Conclusions: We treated the patient with $0.005 \%$ calcipotriol ointment every $12 \mathrm{~h}$ and an oral antihistamine. After 10 weeks, lesions were clinically improved.
\end{abstract}

Keywords: Pityriasis Rubra Pilaris, Circumscribed Juvenile, Calcipotriol

\section{Introduction}

Pityriasis rubra pilaris (PRP) is a group of chronic papulosquamous disorders manifesting hyperkeratotic follicular papules and forming salmon-colored plaques with white scales and commonly accompanied by palmoplantar keratoderma $(1,2)$. The peak incidence of PRP is in early childhood (0-10-years-old), late childhood (11-19-yearsold), and adulthood (40-60-years-old) with an approximate prevalence of 1:5,000 to 1:50,000 $(3,4)$. Children are less affected than adults and approximately include $40 \%$ of all PRP cases. In children, PRP is more common in boys than in girls with a ratio of 3:2 (5).

The PRP treatment remains challenging, especially for some cases unresponsive to topical or systemic treatment. The paucity of the case makes it difficult to do controlled clinical trials to evaluate the efficacy and safety of the treatment. Published controlled clinical trials in PRP are not available up to now; therefore, the treatment of PRP is commonly based on case reports and case series $(5,6)$. Topical calcipotriol is used as the first-line topical therapy even though there is no study to prove the effectiveness (1).

\section{Case Presentation}

A four-year-old boy presented with a chief complaint of scaly red lesions on his elbows, knees, and back associated with gradual thickening palms and soles since he was 3.5-months-old, with no history of trauma. We noticed the appearance of papules at his fingers and back of his hands. The papule and plaques appeared simultaneously and were not progressive. No family member had the same complaint. The patient used baby soap for daily cleansing and coconut oil as a daily moisturizer. He had been treated with $2.5 \%$ hydrocortisone cream for about one year without any improvement.

The general physical examination was within normal limits. In a dermatologic examination, we found erythematous plaques on his elbows and knees, hyperkeratotic papules at his fingers with nutmeg grater signs (Figure 1), and palmoplantar keratoderma with a waxy appearance. The severity was determined by the Psoriasis area and severity index (PASI), as there was no guideline to monitor the disease severity in PRP; the patient got a PASI score of 3. The dermoscopic examination of lesions showed white scales in salmon-colored background and hairs in the center (Figure 2).

Routine blood examination, thyroid function, and Creactive protein were normal and ASO and rheumatoid factor were negative. The histopathologic examination revealed alternating parakeratosis and orthokeratosis in vertical and horizontal directions (checkerboard pattern) suitable for PRP histopathologic findings; hyperplasia psoriasiform and suprapapillary plate thickening were also found in this case. The dermis was filled with fibrocollage- 

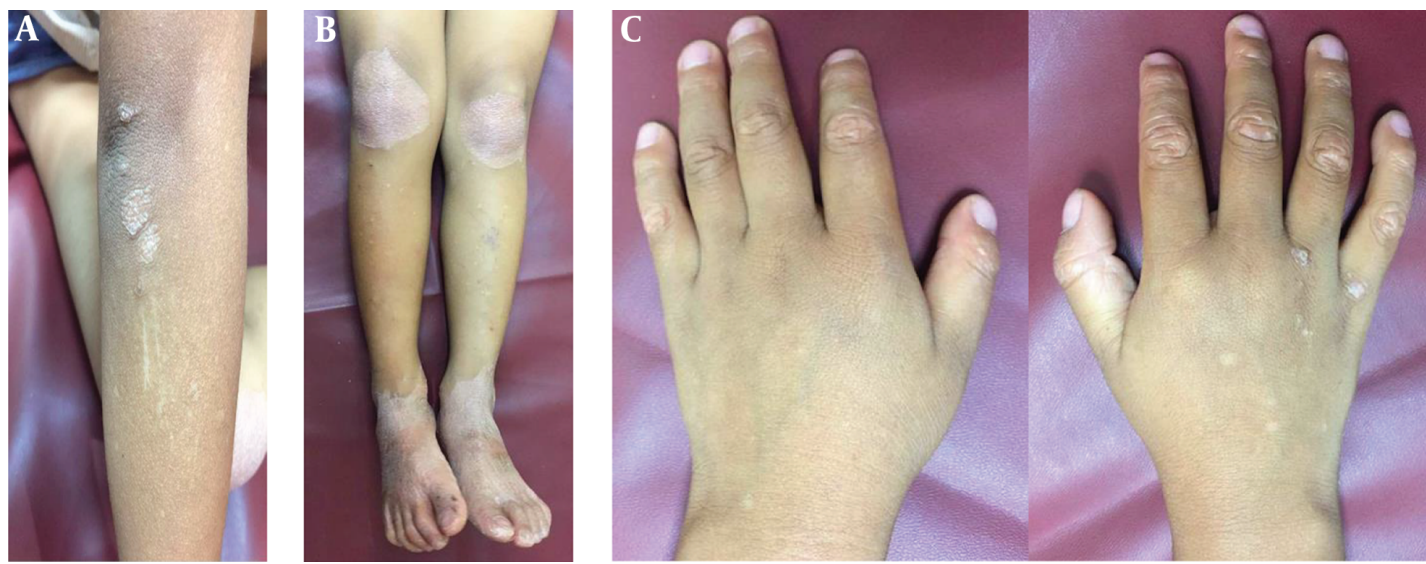

Figure 1. Orange-yellow plaque, white scale on A) elbow; B) knee; and C) finger

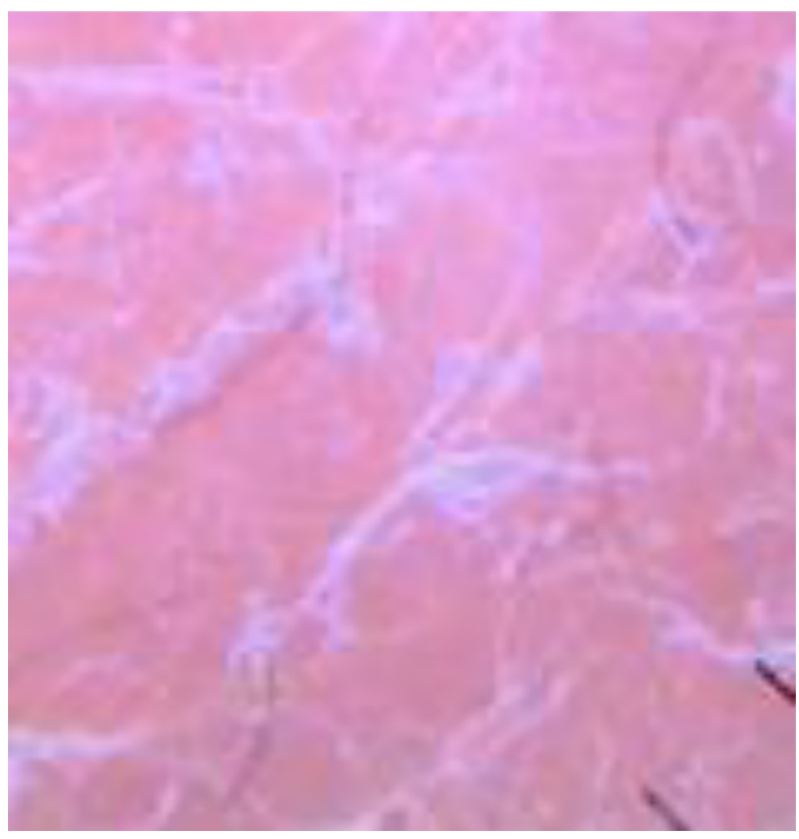

Figure 2. White scales, orange-yellow background, and hair (pilaris)

nous tissue, lymphocytic infiltrates in the vessels, hair follicles, and eccrine glands (Figure 3 ).

The patient was diagnosed with circumscribed juvenile PRP(type IV) and treated with $0.005 \%$ calcipotriol ointment every $12 \mathrm{~h}$ and an oral antihistamine. After 10 weeks, lesions were clinically improved (Figure 4) and pruritus reduced. The PASI score decreased to 0.4. The patient is currently using calcipotriol ointment but oral antihistamines have stopped.

\section{Discussion}

Pytiriasis rubra pilaris is a group of papulosquamous disorders characterized by chronic inflammation that manifests as hyperkeratotic follicular papules, forming salmon color plaque topped with white scales, and often accompanied with palmoplantar keratoderma $(1,2)$. Griffiths classified PRP into six types based on clinical characteristics: type I (classic adult), type II (atypical adult), type III (classic juvenile), type IV (circumscribed juvenile), type V (atypical juvenile), and type VI (human immunodeficiency virus-associated) (1). Circumscribed juvenile PRP (type IV) is the most common type of PRP in children, accounting for $25 \%$ of all PRP patients. The onset occurs commonly at pre-pubertal age (3-10-years-old); however, it may manifest as early as less than one-year-old $(5,7)$. This type is characterized by well-demarcated scaly and erythematous plaques on the elbows and knees; these lesions do not progress to widespread types I and III (1), similar to our patient in this case.

The etiology of PRP is still unknown, even though it has been found since the early 19 th century $(1,8)$. There are several theories associated with this condition, such as vitamin A deficiency, low-level retinol-binding protein (RBP), autoimmune diseases, traumas, genetic factors, infections, and carcinomas. In most cases, the triggering factors of PRP are unknown $(9,10)$.

Genetic factors with an autosomal dominant of inheritance also play a role in PRP (1). Family history of PRP is found in $6.5 \%$ of the cases and most of the familial cases belong to type $\mathrm{V}$ (atypical juvenile) (11). A genetic factor that can cause PRP is the mutation in CARD14, which is often found in the majority of patients with PRP; the NK-kB signal activator has also a role in skin inflammation (8). Our pa- 

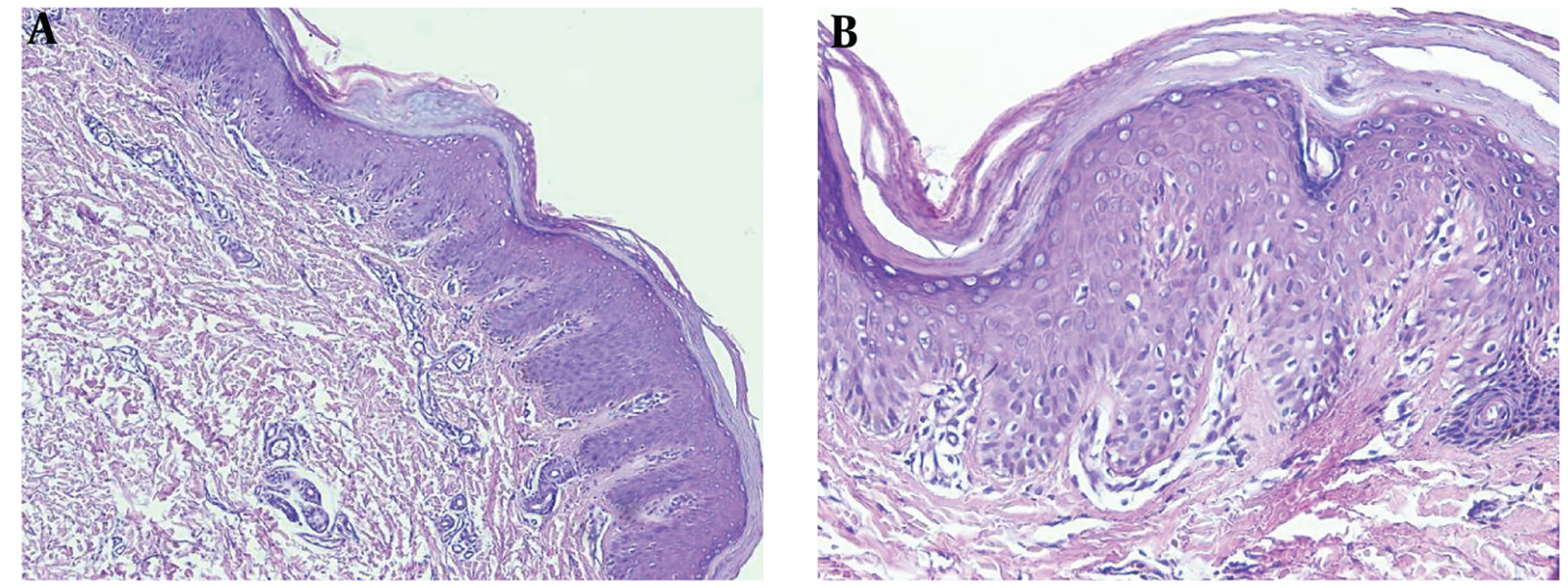

Figure 3. Histopathologic examination with objective magnification $10 \times$; A, psoriasiform hyperplasia; B, alternating parakeratosis and orthokeratosis in vertical and horizontal directions or checkerboard pattern.

tient had the characteristic signs of circumscribed juvenile PRP, i.e. salmon color scaly papules and plaques with welldefined borders on the elbows and knees; palmoplantar keratoderma, and follicular keratotic papules in the back of fingers and feet, associated with pruritus. The initial appearance of lesions was located on the back of hands and feet, progressing to knees, elbows, and fingers. We need further research to prove whether the patient in our case has a mutation of CARD14.

Psoriasis is the major entity for PRP differential diagnosis. The presence of palmoplantar keratoderma, keratotic follicular papules, the classic island of sparing of the trunk, a finer scale, and family history of psoriasis help differentiate PRP from psoriasis (5). In PRP, dermoscopy shows yellow and white scales and keratotic plugs (black circle) in the yellow-red-black ground, while psoriasis shows white scales in light red background (12). The absence of both neutrophilic migration towards the epidermis and Munro's microabscesses in histopathologic findings can help differentiate PRP from psoriasis (5).

The characteristic histopathologic findings of PRP are alternating parakeratosis and orthokeratosis horizontally and vertically, also known as the checkerboard pattern. Psoriasiform hyperplasia, suprapapillary plate thickening, keratinous plug in the infundibular follicle, and perivascular lymphocytic infiltrate are commonly found $(1,13)$. The paucity of the case makes it difficult to do controlled clinical trials to evaluate the effectiveness and safety of the treatment. Previous publications regarding PRP treatment were only case reports or case series $(1,8)$. Generally, the treatment of PRP involves topical, systemic, or physical treatment; the combination of these treatments is also warranted (1).

First-line therapy of PRP includes emollients, keratolytics, and vitamin D3 for topical treatment, while systemic treatment includes retinoids, methotrexate, and triple antiretroviral (for HIV-associated type). Other physical modalities such as photochemotherapy, phototherapy, and extracorporeal photopheresis also can be used for PRP treatment (1). Calcipotriol is a synthetic vitamin D3 ana$\log$ (calcitriol) that binds to vitamin D3 receptor in keratinocytes. Vitamin D inhibits keratinocyte proliferation, epidermal differentiation, inflammation by inhibition of IL-2 and IL-6, IFN-gamma transcription, granulocytemacrophage colony-stimulating factor (GM-CSF) messenger mRNA, cytotoxic T cell, NK cell, and the release of arachidonic acid from neutrophils. The affinity of calcipotriol is similar to that of calcitriol, but the risk of hypercalcemia is lower since calcipotriol is metabolized extensively in topical use. Calcipotriol has a 100 - 200 times lower risk of hypercalcemia than calcitriol. The maximum dose of calcitriol ointment for children younger than sixyears-old is 30 grams/week $(14,15)$.

Our patient was treated with $0.005 \%$ calcipotriol ointment every $12 \mathrm{~h}$. The monitoring of treatment noted a reduction of $90 \%$ in the PASI score after 10 weeks. The PASI score was used to evaluate the treatment outcome because no PRP score was available yet. Our patient had a normal calcium level with no side effects after calcipotriol use.

Pityriasis rubra pilaris is a self-limiting condition with expected spontaneous remission within two years. However, spontaneous remission is less likely to occur in circumscribed juvenile PRP (type IV) than in classical PRP (type I or III), occurring in $32 \%$ of the patients. Lesions in 

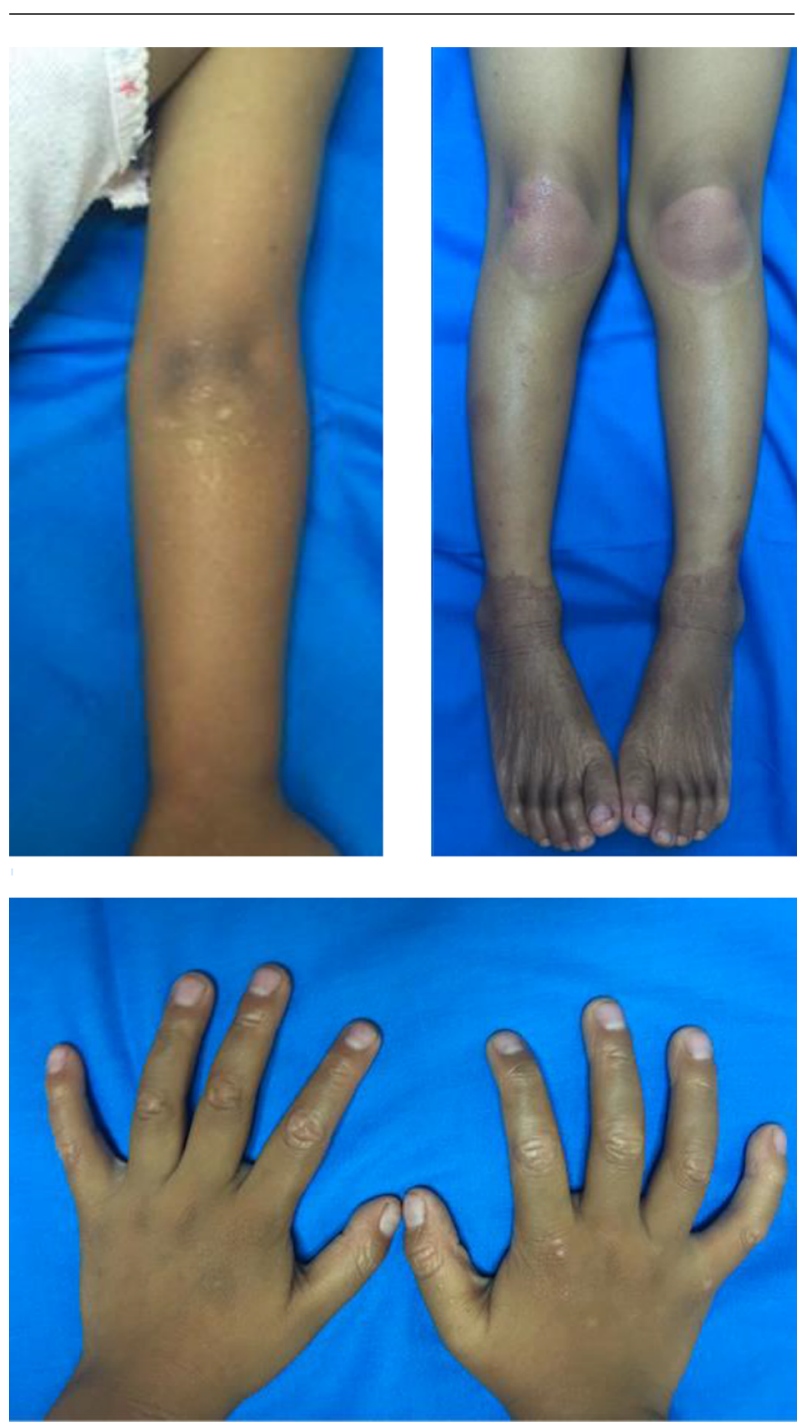

Figure 4. Lesions with clinically improved hypo-hyperpigmented patch

circumscribed juvenile PRP could be settled for more than three years in $67 \%$ of the patients $(5,8)$. Our patient had lesions for more than three years without spontaneous remission.

Prognosis is not related to an acute or gradual onset of PRP. The recurrence was found in $17 \%$ of the patients usually in the same area $(5,8)$. Our patient improved after 10 weeks with no worsening into generalized lesions or erythroderma and without the involvement of other organ systems. Family education is important, as it may recur with varied duration in $17 \%$ of cases (9).

\section{Footnotes}

Authors' Contribution: Case report concept and design: Fitriani Fitriani and Hari Darmawan. Drafting of the manuscript: Nina Roiana and Hari Darmawan. Critical revision of the manuscript for important intellectual content: Inda Astri Aryani and Soenarto Kartowigno.

Conflict of Interests: No conflict of interest is reported.

Funding/Support: This study was not supported financially by anyone.

Informed Consent: Informed consent form was signed.

\section{References}

1. Gerharz DB, Ruzicka T. Pityriasis rubra pilaris. In: Wolff K, Goldsmith LA, Katz SI, Gilchrest BA, Paller AS, Lefel DJ, editors. Fitzpatrick's dermatology in general medicine. 8th ed. New York: McGraw Hill; 2012. p. 27984.

2. Martin KL, Holland KE, Lyon V, Chiu YE. An unusual cluster of circumscribed juvenile pityriasis rubra pilaris cases. Pediatr Dermatol. 2014;31(2):138-45. doi: 10.1111/pde.12260. [PubMed: 24456130].

3. Chu AC. Pityriasis rubra pilaris. In: Griffiths C, Barker J, Bleiker T, Chalmers R, Creamer D, editors. Rook's textbook of dermatology. 9 th ed. London: Wiley Blackwell; 2016. p. 36.1-7.

4. Sehgal VN, Srivastava G. (Juvenile) Pityriasis rubra pilaris. Int J Dermatol.2006;45(4):438-46. doi:10.1111/j.1365-4632.2006.02666.x. [PubMed: 16650174].

5. Wood GS, Reizner GT. Other papulosquamous disorders. In: Bolognia JL, Jorizzo JL, Shaver JV, editors. Dermatology.3rd ed. New York: Elsevier Saunders; 2012. p. 162-5.

6. Sehgal VN, Srivastava G, Verma P. Pityriasis rubra pilaris: evolution of challenges in promising treatment options. Skinmed. 2012;10(1):18-23. [PubMed: 22324172].

7. Paller AS, Mancini AJ. Papulosquamous and related disorders. In: Paller AS, Mancini AJ, editors. Hurwitz clinical pediatric dermatology. 4th ed. Edinburgh: Elsevier Saunders; 2011. p. 81-4. doi: 10.1016/b978-14377-0412-9.00004-6.

8. Klein A, Landthaler M, Karrer S. Pityriasis rubra pilaris: A review of diagnosis and treatment. Am J Clin Dermatol. 2010;11(3):157-70. doi: 10.2165/11530070-000000000-00000. [PubMed: 20184391].

9. Arnold AW, Buechner SA. Circumscribed juvenile pityriasis rubra pilaris. J Eur Acad Dermatol Venereol. 2004;18(6):705-7. doi: 10.1111/j.14683083.2004.01039.x. [PubMed: 15482302].

10. Ross NA, Chung HJ, Li Q, Andrews JP, Keller MS, Uitto J. Epidemiologic, clinicopathologic, diagnostic, and management challenges of pityriasis rubra pilaris: A case series of 100 patients. JAMA Dermatol. 2016;152(6):670-5. doi: 10.1001/jamadermatol.2016.0091. [PubMed: 26963004]. [PubMed Central: PMC6262840].

11. Fung YP. Pityriasis rubra pilaris: An update review. HK Dermatol Venereol Bull. 2001;9:10-6.

12. Abdel-Azim NE, Ismail SA, Fathy E. Differentiation of pityriasis rubra pilaris from plaque psoriasis by dermoscopy. Arch Dermatol Res. 2017;309(4):311-4. doi: 10.1007/s00403-017-1727-2. [PubMed: 28280914].

13. Weedon D. Weedon's skin pathology. 3rd ed. Edinburgh: Churchil Livingstone/ Elsevier; 2010.

14. Hinds G, Helfrich Y, Sachs D, Kang S. Topical vitamin D3. In: Wolverton SE, editor. Comprehensive dermatologic drug therapy. 3rd ed. New York: Elsevier; 2013. p. 543-9.

15. Jena A, Dash M, Panda M, Patro N. Childhood pityriasis rubra pilaris-A case report. J Chem Pharm Res. 2014;6(8):312-4. 